This item was submitted to Loughborough's Institutional Repository (https://dspace.lboro.ac.uk/) by the author and is made available under the following Creative Commons Licence conditions.

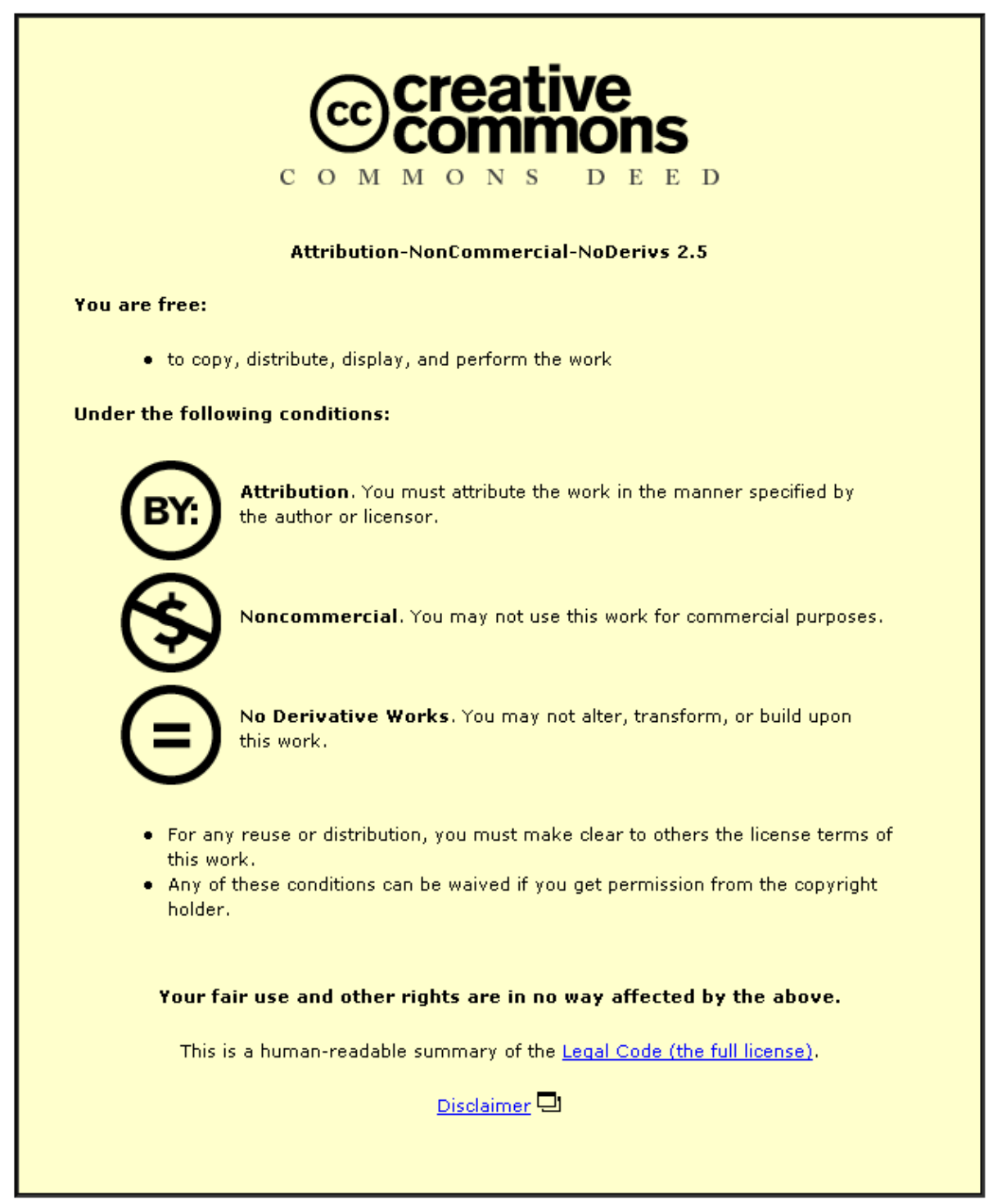

For the full text of this licence, please go to: http://creativecommons.org/licenses/by-nc-nd/2.5/ 


\title{
CONDUCTIVITY OF ACID ZINC AND COPPER PLATING
}

\author{
SOLUTIONS.
}

\author{
D.R.Gabe, M.Li and Z.Ding \\ Dept. of Materials, Loughborough University, LE11 3TU \\ D.R.Gabe@lboro.ac.uk
}

\begin{abstract}
SYNOPSIS
Conductivity data are presented for the common acid solutions (sulphate, chloride) used in the electrodeposition of zinc and copper. Optimised solution concentrations may be defined and the values obtained indicate the dominant ions which are present in solution at specific concentrations and temperatures.
\end{abstract}

\section{INTRODUCTION}

The problem of solution conductivity for electrodeposition processes is not new and has been considered previously in a number of contexts [1-2]. Its importance is certainly technical but its cost importance is usually regarded as small when compared to other process costs notably heating/cooling and agitation.

In a recent paper [3] some aspects of conductivity of nickel electroplating solutions were reported and discussed. It was pointed out that solutions are rarely formulated for their conductivity but that optimisation of conductivity could lead to a means of minimising electrical power consumption. This requirement can be especially important for high speed plating including electroforming.

Besides the specific needs of nickel discussed previously, power consumption is an economic issue for both zinc, in the context of electrogalvanizing of sheet, strip and wire, and copper for Printed Circuit Board production; the former demands fast continuous production while the latter has long deposition times demanding long tank occupancy and consequent high plant overheads.For each of these processes acid solutions are the usual formulation choice, sulphate-based for zinc and copper and chloride-based for some zinc operations.

In this investigation some conductivity data have been obtained for relevant solutions and some conclusions noted.

\section{EXPERIMENTAL and RESULTS.}

As before conductivity measurements have been made for various concentrations and temperatures of zinc sulphate and chloride solutions and copper sulphate. A Jenway model 470 Conductivity Meter was used with a special 10:1 ratio cell giving best sensitivity for the highly conducting solutions being studied. Solutions were thermostatically controlled at temperatures from 20 to $60^{\circ} \mathrm{C}$. 


\section{Zinc sulphate.}

It is well-known that sulphuric acid shows a maximum conductivity at $\sim 400 \mathrm{~g} / 1$, see fig. 1 , and that it is therefore pointless using solutions above that concentration. Zinc sulphate does not show such a maximum because its solubility limit is relatively low at $\sim 600 \mathrm{~g} / \mathrm{l}$, see fig.2. Therefore there is no obvious optimised concentration available. Cost limitation relates to not exceeding the maximum for sulphuric acid while maintaining a high zinc level for maximum deposition rate.

Increase of temperature is a well-established way of improving deposition rates both by increasing metal solubility and increasing conductivity. This is illustrated in fig.3. Typically for an increase of temperature from 20 to $50^{\circ} \mathrm{C}$ the conductivity increases by $25-30 \%$.

\section{Zinc chloride.}

Chlorides are less used in electroplating, partly because of their cost and partly because the acid is much more corrosive. Hydrochloric acid exhibits a maximum in conductivity at $\sim 750 \mathrm{~g} / 1$ concentration, see fig.4, a value well-above that normally considered for other reasons. But the notable information for zinc chloride is that it is much more soluble than sulphate, typically a limit of $>1500 \mathrm{~g} / \mathrm{l}$, and that it shows a maximum conductivity at $\sim 400 \mathrm{~g} / \mathrm{l}$ because of its decreasing dissociation at higher solubility levels. Thus high speed electrogalvanizing can be achieved at the expense of electrical power costs with highly concentrated solutions.

\section{Copper sulphate.}

The behaviour of sulphuric acid has been noted (fig.1) and that for copper sulphate is shown in fig.5. The limit of solubility is $\sim 250 \mathrm{~g} / 1$ at ambient temperatures and that accounts for the usual PCB process conditions of 200-250g/l. Additives are used too but have little effect on either conductivity or solubility.

\section{Copper fluoborate.}

An alternative solution for 'high speed deposition' is that of copper fluoborate which was much favoured in the 1970s, since when it has been less used on grounds of cost and the fact that agitation is now more effective for sulphate solutions. Its much higher conductivity shows a classical maximum characteristic of high solubility salts (fig. 6).

\section{Copper pyrophosphate.}

The pyrophosphate solution is operated at near neutral $\mathrm{pH}$ and has been used for specialist applications where it can be brightened with additives and treated as a complexed solution, especially if ammonia is added as a 'stabiliser'. Its lack of use can be attributed to the ammonia effect when it slowly evaporates thus requiring constant control.

\section{DISCUSSION.}

The relation of optimal conductivity to commercial solution compositions has already been noted but it is not necessarily the only consideration; often the fact that dragout of concentrated solutions leads to greatest loss in rinsing can be vital. It may further be noted that present formulation practice does not lead to significantly different solution concentrations.

Values of solution conductivity are primarily dependant on the dominant conducting ion and use 
of Arrhenius graphical plots can sometimes indicate changes of a dominant ion. The Arrhenius plot derives from the equation:

$$
\text { conductivity }=\text { constant } \exp -\mathrm{Q} / \mathrm{RT}
$$

such that a plot of $\log$ (conductivity) versus $1 / T$ indicates the activation energy $Q$ which characterises the dominant ion.

Separate Arrhenius plots have been made for the two zinc solutions. Both zinc sulphate (fig. 8) and zinc chloride (fig. 9) show clear lines but with a distinct break, or change of slope, at a temperature of about $35^{\circ} \mathrm{C}$. This must be due to a change of dominant ion probably related to hyrolysis or solvation and does not significantly affect the mechanism of deposition but just the exact conductivity value.

The Arrhenius plots for copper sulphate at two different concentrations (fig.10) are quite normal and indicate that conductivity is due to the same ion at all times - cupric $\mathrm{Cu}^{2+}$. Although the cuprous ion, $\mathrm{Cu}^{+}$, is well-established as a species it is apparently not present in this solution.

The results presented do not lead to any recommended change of solution formulation but suggest that in the past conductivity has been a factor without being stated explicitly.

The conductivity data also demonstrates the technical importance of zinc chloride and copper fluoborate for high speed electrodeposition due to their higher solubilities and conductivities. The fact that they are not widely used relates to other considerations such as solution corrosivity, cost and necessary effluent treatment. Although the cost of power used in electrodeposition can be important it has usually been seen as a relatively minor cost when compared to these other factors in a careful process cost analysis.

\section{CONCLUSIONS}

Conductivity data for acid copper and zinc solutions are reported and they have been related to the level of salt solubility and possible changes of dominant conducting ion in solution.

The technical virtues of zinc chloride and copper fluoborate for high speed deposition have been noted although other factors may preclude their use in practice.

\section{REFERENCES.}

1. G.Guvendik and D.R.Gabe. Trans Inst Met Fin 1999, 77, 127.

2. D.R.Gabe, L.Chen, M.Li and Z.Ding. Proc. Nicholas Spyrellis Memorial Symposium, Technical University of Athens, 2009.

3. D.R.Gabe and L.Chen. Trans Inst Met Fin 2009, 87, 8. 


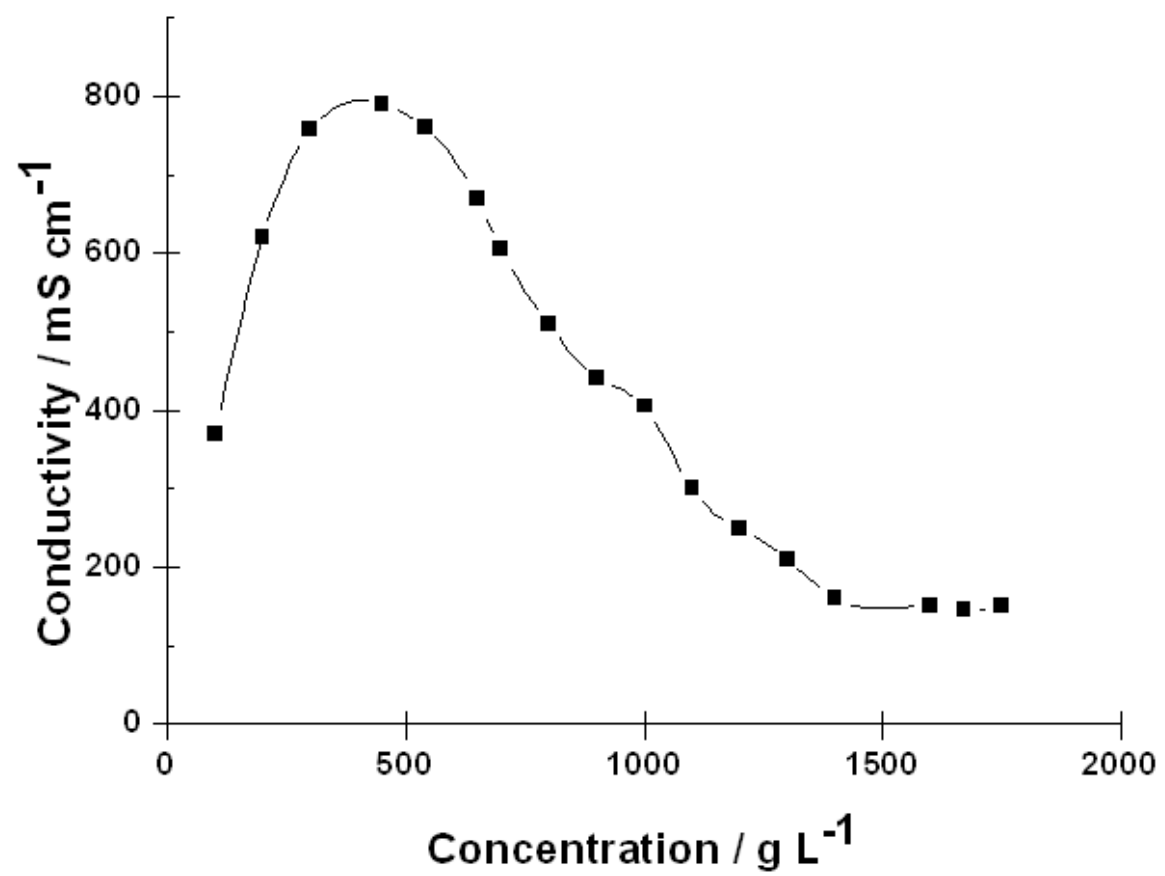

Fig.1. Conductivity of sulphuric acid solutions at $20^{\circ} \mathrm{C}$

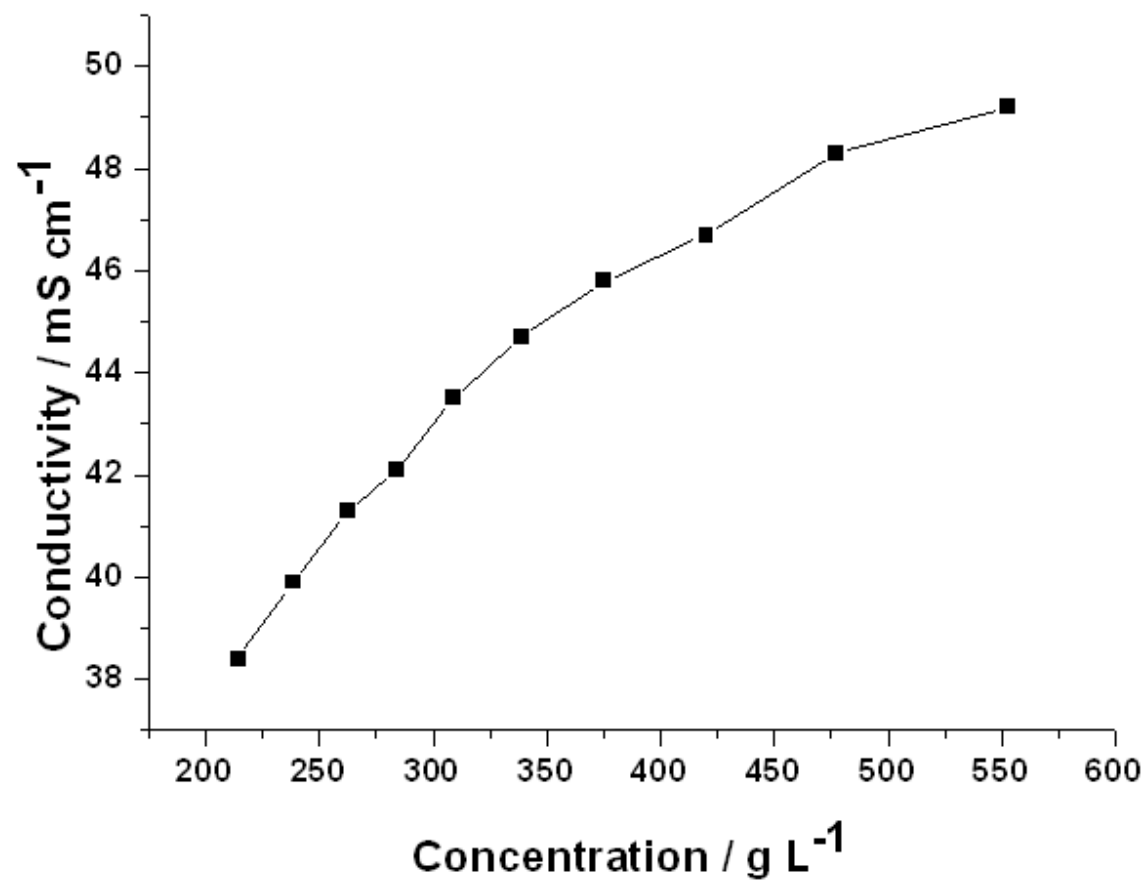

Fig. 2. Conductivity of zinc sulphate solutions at $20^{\circ} \mathrm{C}$. 


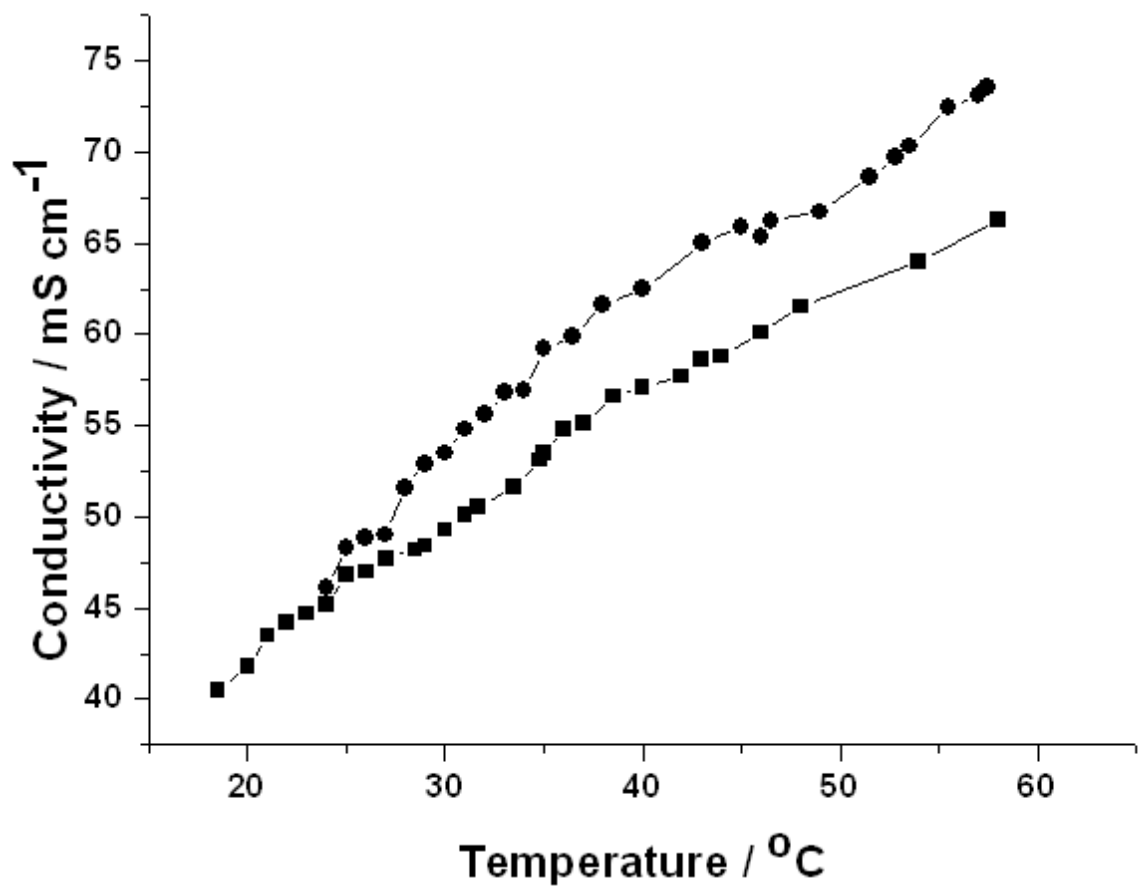

Fig. 3. Conductivity versus temperature of zinc sulphate at 400 and $500 \mathrm{~g} \mathrm{~L}^{-1}$ oncentration. $\mathbf{\text { is }}$ for $400 \mathrm{~g} \mathrm{~L}^{-1}$; • is for $500 \mathrm{~g} \mathrm{~L}^{-1}$.

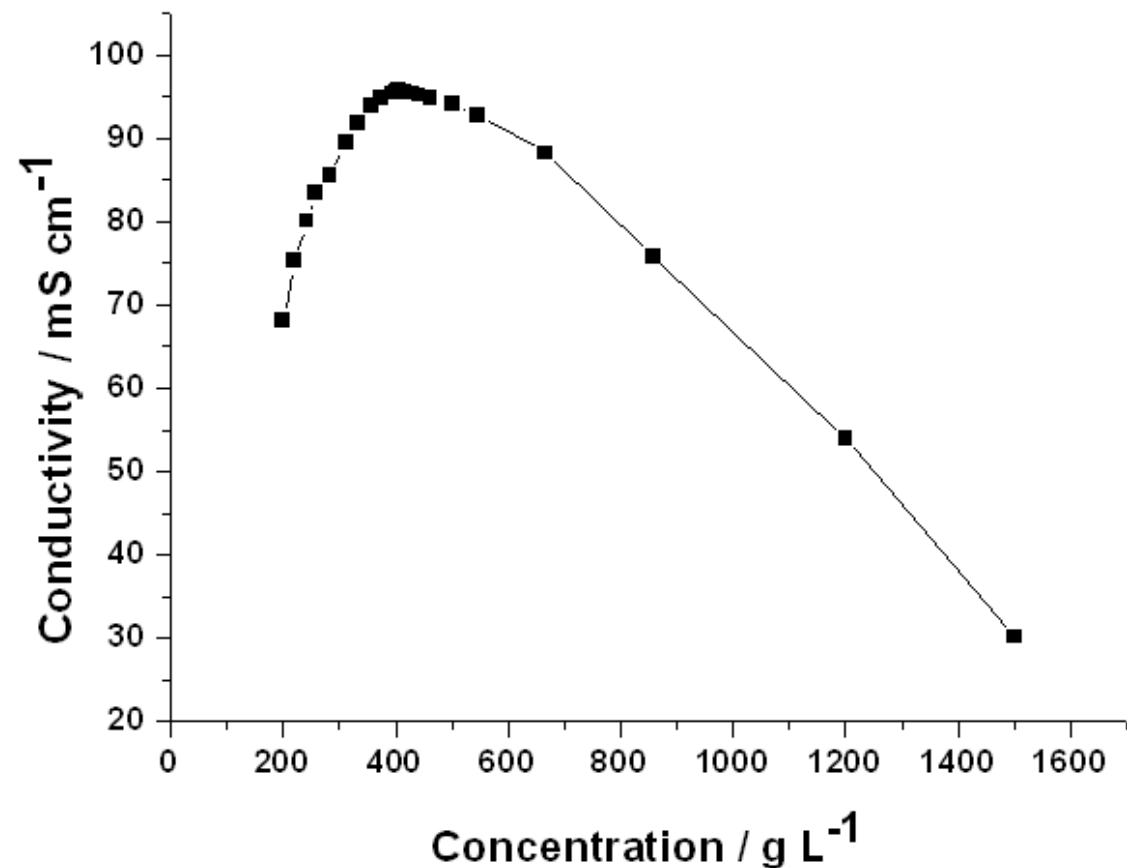

Fig.4. Conductivity versus concentration of zinc chloride at $25^{\circ} \mathrm{C}$ 


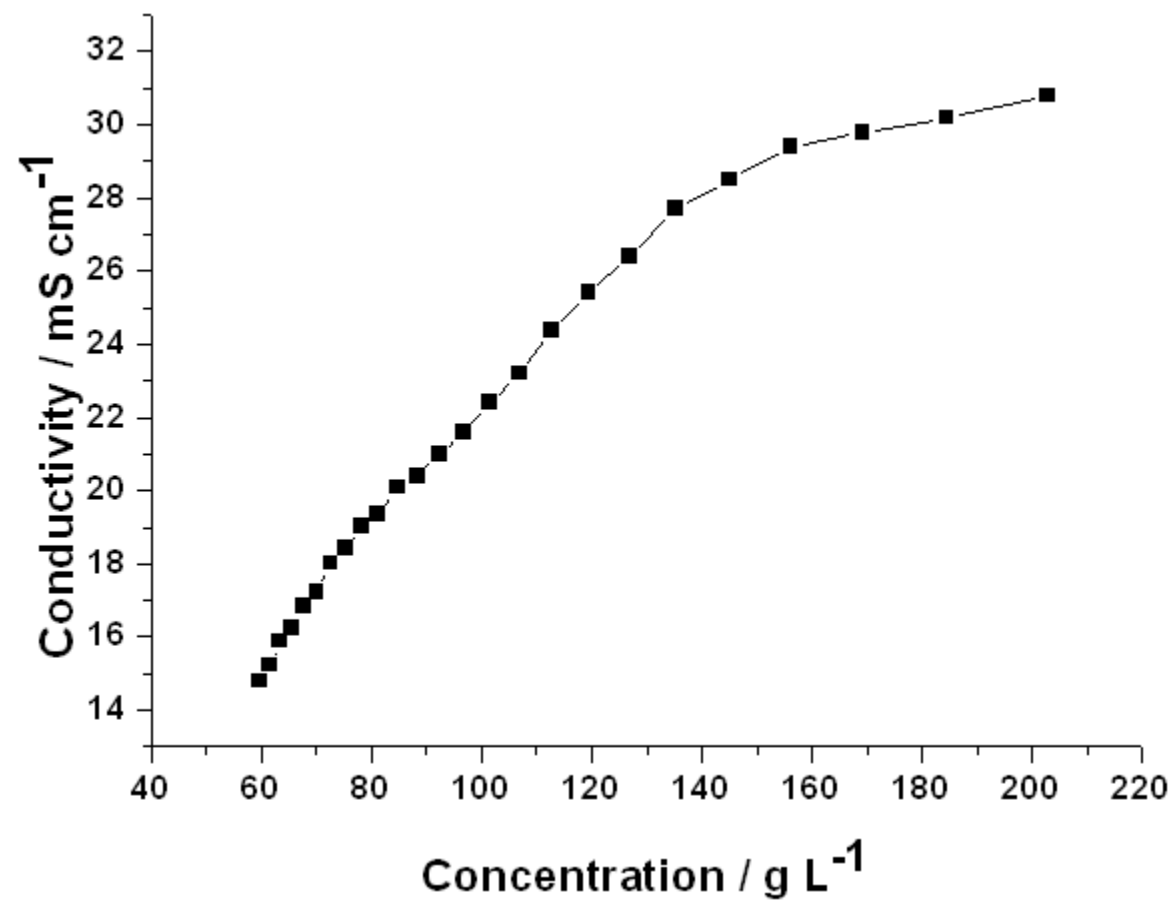

Fig.5. Conductivity of copper sulphate at various concentrations $(\mathrm{g} / \mathrm{l})$ at $20^{\circ} \mathrm{C}$.

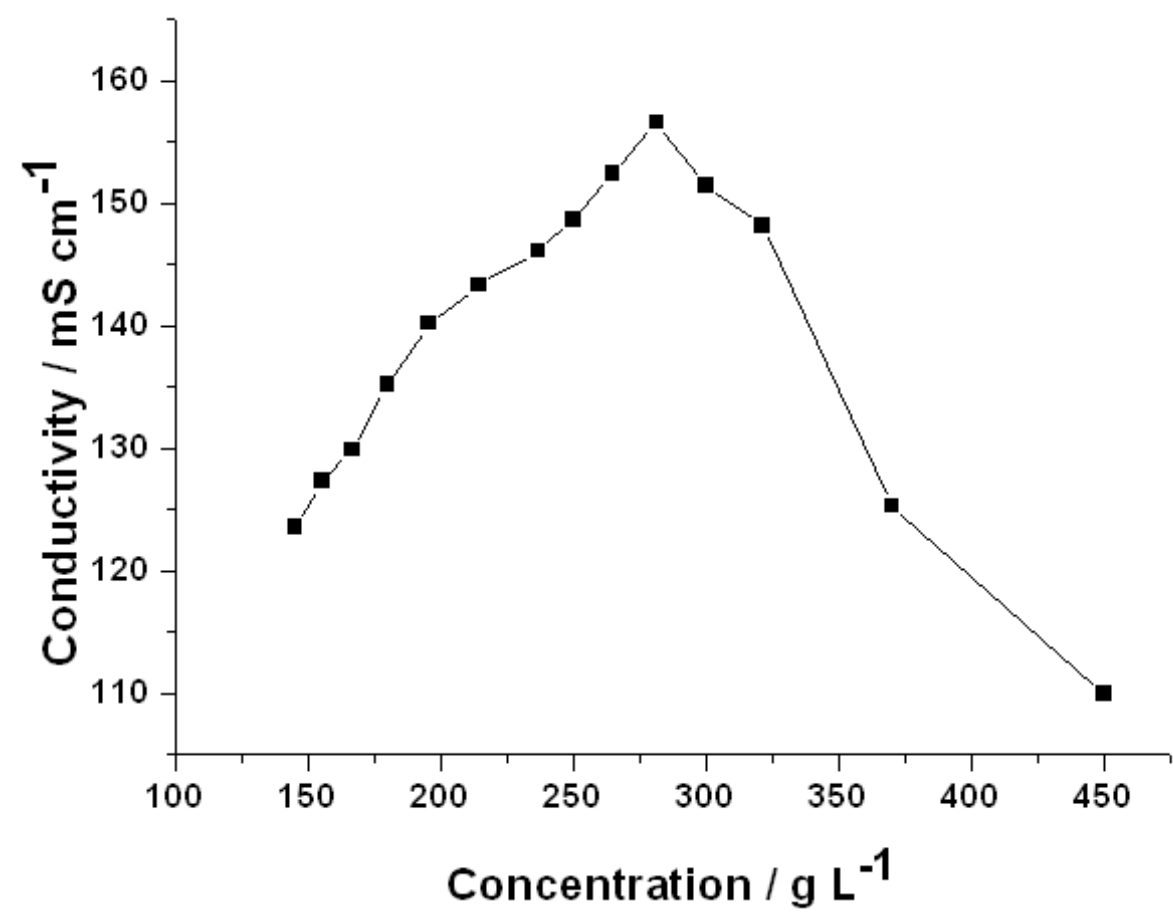

Fig. 6. Conductivity $(\mathrm{mS} / \mathrm{cm})$ v. solubility $(\mathrm{g} / \mathrm{l})$ for copper fluoborate. 


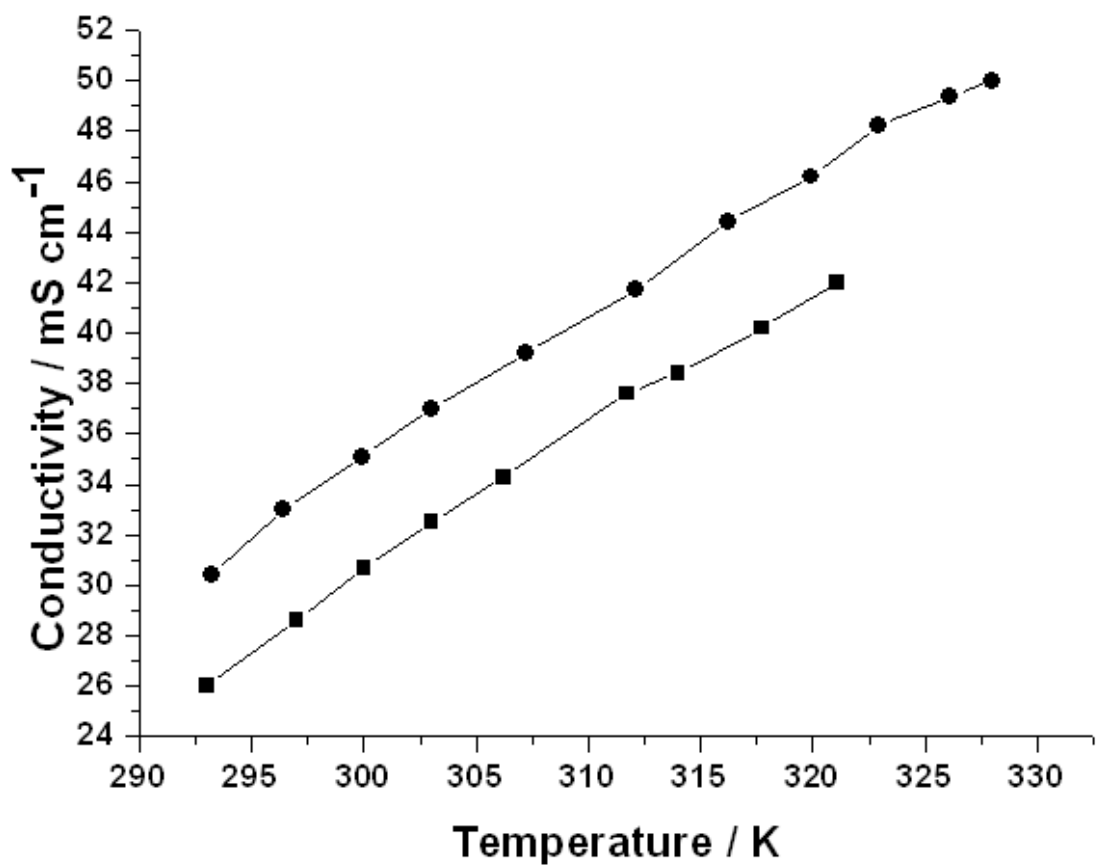

Fig. 7. Conductivity data $(\mathrm{mS} / \mathrm{cm})$ for copper pyrophosphate $(\mathrm{g} / \mathrm{l})$ with and without ammonia additions. - is for without ammonia additions; • is for with ammonia additions.

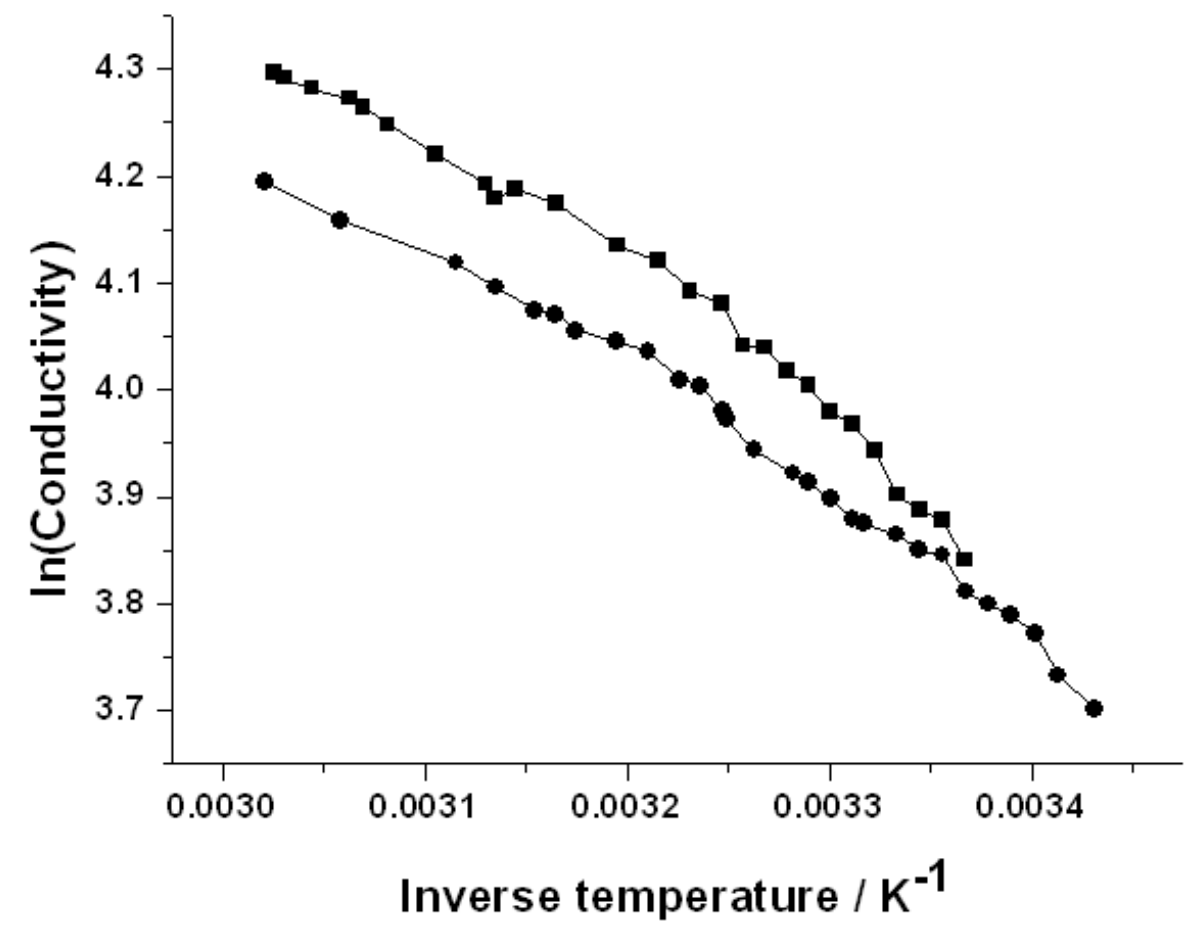

Fig. 8. Arrhenius plot for two zinc sulphate solutions. $\square$ is for $500 \mathrm{~g} \mathrm{~L}^{-1}$; • is for $400 \mathrm{~g}$ $\mathrm{L}^{-1}$. 


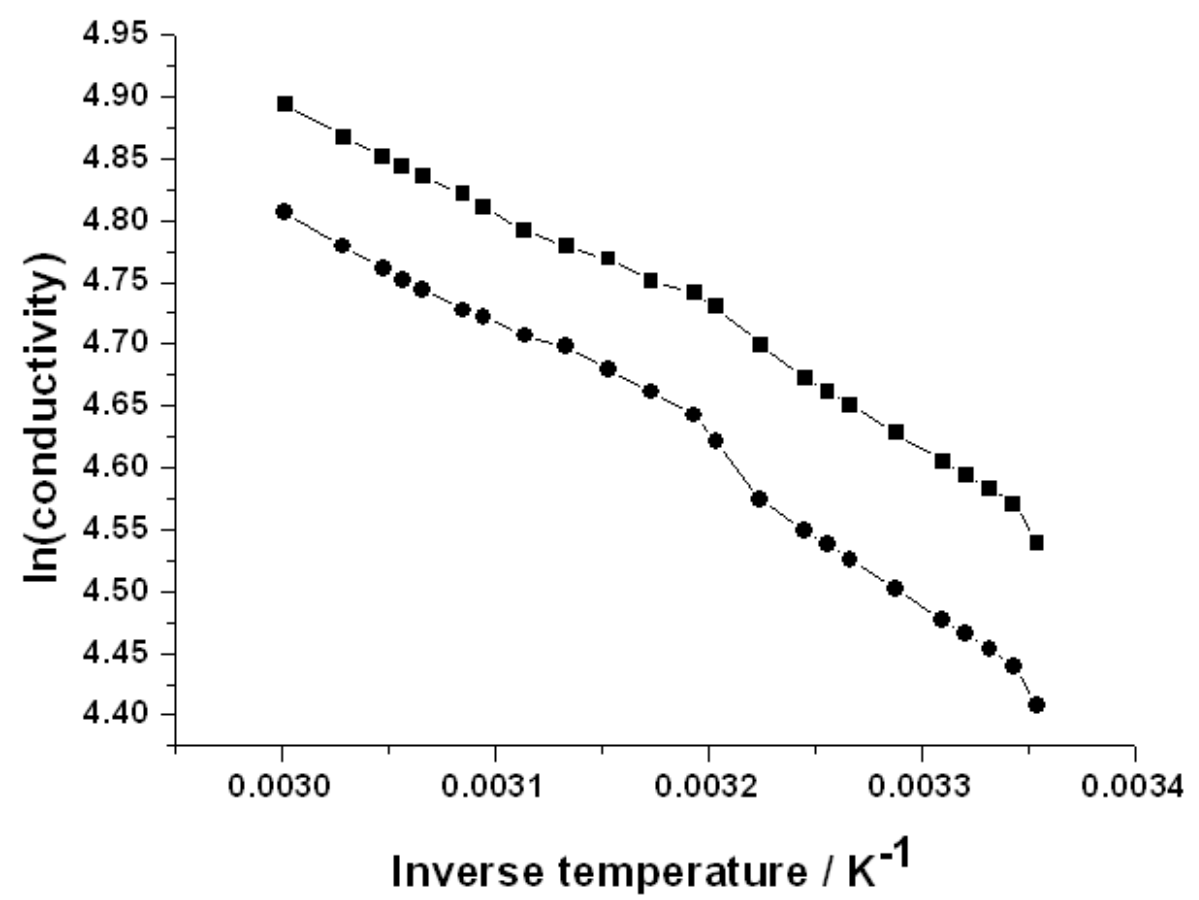

Fig. 9. Arrhenius plots for two zinc chloride solutions. $\boldsymbol{\text { a }}$ is for $400 \mathrm{~g} \mathrm{~L}^{-1}$; • is for 250 $\mathrm{g} \mathrm{L}^{-1}$.

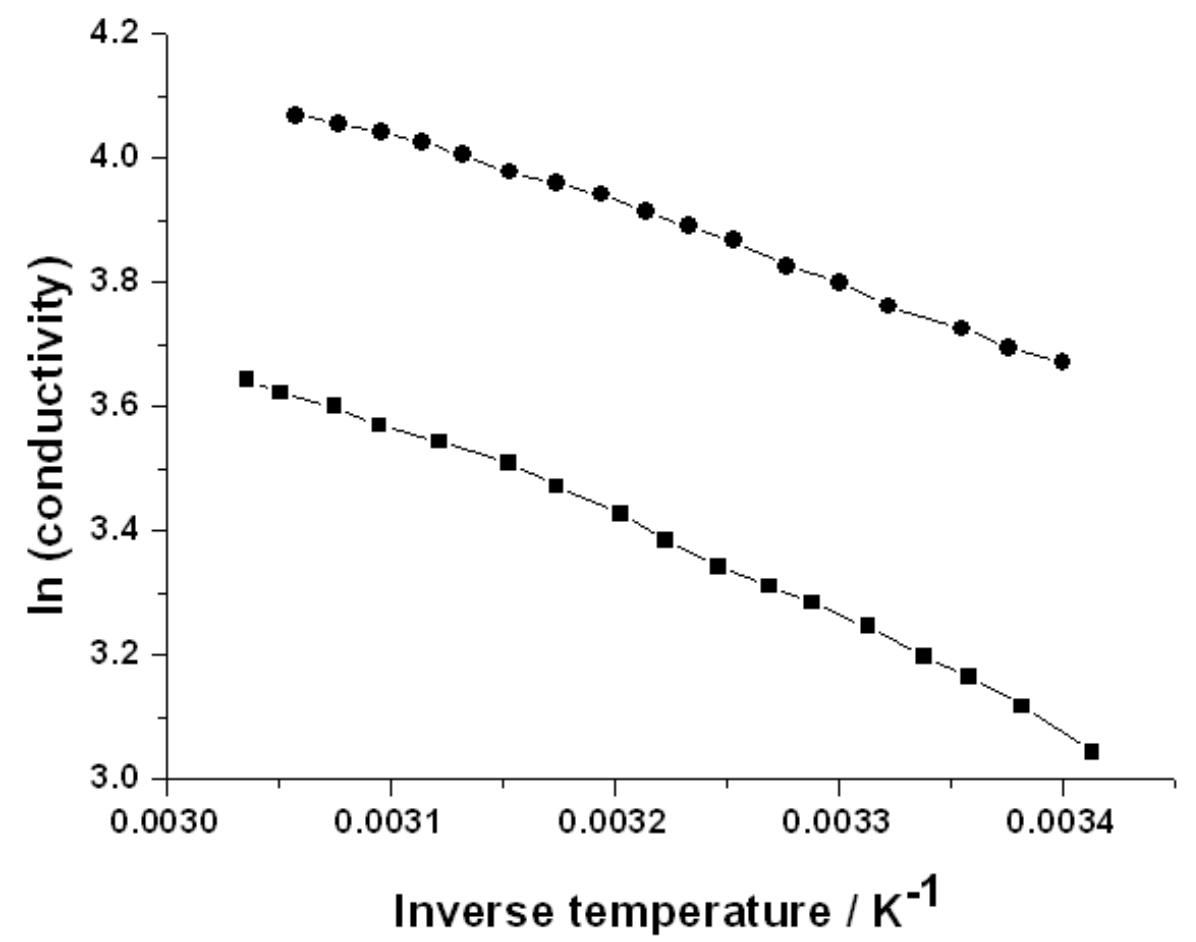

Fig. 10. Arrhenius plot of $\log$ conductivity v. $\mathrm{T}^{-1}$ for copper sulphate solution. $\boldsymbol{\square}$ is for $160 \mathrm{~g} \mathrm{~L}^{-1}$; $\bullet$ is for $230 \mathrm{~g} \mathrm{~L}^{-1}$. 